\title{
Range Claypan Soil Improvement: Properties Affecting Their Response to Mechanical Treatment
}

\author{
E.M. WHITE AND F.R. GARTNER
}

\begin{abstract}
Improvement efforts for claypan range sites by mechanical treatment can be grouped into those that increase water infiltration, disrupt the exchangeable-Na-rich claypan layer, mix the claypan layer with other layers, or combinations of treatments. The beneficial effect of a treatment on range productivity depends mainly on the specific soil characteristics or adapting the treatment to the soil. Spacings between contour furrows, ripper teeth, or similar devices probably should coincide with the distance between large natural soil structure boundaries for maximum lasting effects.

Mechanical treatments designed to improve claypan soils with high exchangeable Na have had varied success, and attempts to predict the vegetative response have not always been accurate. Unfortunately, research scientists are inclined to publish positive results more than negative results because the latter are often difficult to explain. Possibly, a general discussion of the properties of claypan soils that might be altered by mechanical treatments would encourage more accurate description of areas and the reporting of negative as well as positive responses.
\end{abstract}

Authors are professor of plant science (soils) South Dakota State University Brookings 57007; and associate professor of animal science (range management) South Dakota State Univ., Agr. Res. and Extension Center, 801 San Francisco St., Rapid City 57701 . 1634.

This report is a contribution from the South Dakota Agr. Exp. Sta. J. Series No. Manuscript received May 24, 1979.

\section{Claypan Soils}

Claypan range soils generally have 3 - to 30 -foot diameter shal low depressions with sparse vegetation over at least 20 percent 0 the landscape. The depressions have a claypan that has or once har sufficient exchangeable $\mathrm{Na}$ to cause dispersion of clay particles These soils have been called solodized solonetz, slickspots, o panspots but today would be included in categories with natri horizons (Soil Survey Staff 1975). A compact structure develop that is very slowly permeable to water. Ponds, which form on th surface, frequently evaporate before the claypan is moistened $t_{1}$ recharge the soil water for plant growth. Thus, the claypan soil accumulate less water for plants than the adjacent soils lacking th claypan.

Soils adjacent to claypan depressions may have (1) a claypa below a friable surface layer, (2) a relict claypan that is low i: exchangeable $\mathrm{Na}$, or (3) no evidence of a claypan. The lower so layers frequently have high exchangeable $\mathrm{Na}$ and salinity. In som areas the content of $\mathrm{Na}$ and other kinds of salt is high in the surfac layer. Vegetation usually forms a continuous cover on the adjacen soils if grazing management has been adequate.

Claypan soils in different geographic locations are formed in variety of parent matcrials. These may range from gravel to ver fine clay and occur on excessively drained steep upland slopes $t$ seasonally wet lowlands or floodplains. Some parent material have exchangeable $\mathrm{Na}$ because a fluctuating water table or see 
water carried $\mathrm{Na}$ salts into the soil profile. Others, particularly sedimentary rocks, had high exchangeable $\mathrm{Na}$ or $\mathrm{Na}$ salt contents when they were exposed to soil formation by erosion. Soils, formed in a short time from parent material recently exposed by erosion or deposited by wind or water, have weakly developed thin horizons. In older landscapes, thicker soil horizons and profiles have formed with more strongly developed structure and with more organic matter.

\section{Formation of the Claypan}

The individual clay and silt particles in most soils are aggregated together to form stable structural units. This aggregation breaks down in claypan soils so that minute individual mineral and organic fragments are free to move in water draining downward through the soil profile. The moving particles collect in small pores, plug them, and impede the downward flow of water. Once clay lodges in the pores, the slowly permeable claypan tends to persist even though the chemical environment of the clay changes from the dispersed state to the flocculated state under which stable structural units form.

The dispersed condition is caused by the exchangeable $\mathrm{Na}$ cations (Frenkel et al. 1978) that surround the negatively charged soil particles, mainly clay or organic material. A positively charged shell of cations forms around the negatively charged particles. Two adjacent clay particles with positively charged shells repel each other because both have the same charge on the outside. If the exchangeable cations are di- or trivalent they are bound more tightly to the clay surface and are neutralized. The positively charged shell then becomes weakened to the extent that the clay particles no longer repel one another and aggregates become stable. If sufficient sodium salts are present, the added sodium cations in the solution also are attracted to the negatively charged clay. Thus, more exchangeable Na cations are on the mineral surface so that the charge of the cation shell is reduced, and the clay does not disperse.

If both exchangeable divalent (trivalent) and $\mathrm{Na}$ cations are present, the $\mathrm{Na}$ tends to be excluded from the clay surface and forms a positive shell that can result in dispersion. Dispersion occurs if 10 to 15 percent or more of the exchangeable cations are $\mathrm{Na}$ and the soluble salt content is low. In addition, exchangeable $\mathrm{Na}$ probably is associated with the smaller clay particles and the divalent cations with the larger clay particles, at least with montmorillonite (McAtee 1958).

$\mathrm{Ca}$ ions are usually the main exchangeable cation in most soils, although $\mathrm{Mg}$ is important in some. Apparently $\mathrm{Ca}$ and $\mathrm{Mg}$ cations are attracted to the clay surface with about the same forces (Clark 1966). Some studies have suggested that $\mathrm{Mg}$ is bonded less strongly than Ca in some soils (Singh and Moorthy 1965), but Mg is not considered as important as $\mathrm{Na}$ in causing dispersion (Chi et al. 1977).

\section{Movement and Degradation of the Claypan}

A claypan forms where exchangeable $\mathrm{Na}$ is abundant enough to cause dispersion and the salt content is too small to prevent it. In most claypan soils, exchangeable $\mathrm{Na}$ and soluble salt both increase with depth due to the leaching of the upper soil. Soils with some subsoil drainage lose salt more rapidly than the exchangeable $\mathrm{Na}$. Salt is usually high enough in most of the lower subsoil to prevent dispersion so that dispersion can occur only in a thin layer where leaching has removed the salt but not the exchangeable Na. This dispersed layer moves downward as both the $\mathrm{Na}$ and salt are leached.

Exchangeable $\mathrm{Na}$ is gradually replaced by $\mathrm{Ca}(\mathrm{Mg}, \mathrm{K}, \mathrm{H})$ in the upper part of the dispersed layer. These cations are released during the weathering of most silicate minerals and the decay of the plant remains returned to the soil. Some of the dispersed clay probably moves downward (Frenkel et al. 1978) in the soil but at least part of it breaks down by weathering to release the cations that replace $\mathrm{Na}$ (Barshad 1960). Thus, claypan soils with thick friable surface layers need not have a more clay-rich dispersed horizon than adjacent claypan soils that lack the friable surface layer. At least the friable surface layer probably has less clay than it had before the sodium moved downward.

If the exchangeable $\mathrm{Na}$ was the minimum needed for dispersion and $\mathrm{Na}$ leaching was rapid, the claypan may be left nearly intact with a low $\mathrm{Na}$ content. Structure is not improved by the leaching because it is a physical condition caused by clay filling the pores of the claypan. This relict layer with poor structure is more evident if the parent material had a fine texture (White 1961) rather than a coarser one, probably because there is more clay available to create the layer. Soils that have this relict structure, or are in the process of developing it, probably are the ones most suited to mechanical treatment.

\section{Chemical Variables in Claypan Soils}

Quantities of the different exchangeable cations vary widely within tracts (White 1964) and between tracts as mentioned earlier. In addition, the amounts and solubility of $\mathrm{Ca}, \mathrm{Mg}, \mathrm{Na}$, and $\mathrm{K}$ carbonate, bicarbonates, and sulfates are variable. $\mathrm{CaCO}_{3}$ is present in most parent materials. Exceptions include the so-called acid parent materials of some shale beds in western South Dakota or bituminous materials where sulfides occur. If $\mathrm{CaCO}_{3}$ is the only moderately soluble compound present, the $\mathrm{pH}$ may range from about 8.2 to 84. If $\mathrm{Na}_{2} \mathrm{CO}_{3}$ or $\mathrm{NaHCO}_{3}$ is present, a much higher pH occurs. $\mathrm{CaCO}_{3}$ is essentially insoluble at a pH above 9 or 10 (Nakayama 1969) so that sodium can dominate the exchange complex. At a lower $\mathrm{pH}, \mathrm{CaCO}_{3}$ normally dissolves sufficiently when water is added to dry soil and the $\mathrm{Ca}$ cations replace the exchangeable $\mathrm{Na}$ which then moves away from the clay surface. The reverse occurs as the soil dries and $\mathrm{CaCO}_{3}$ precipitates because it is less soluble than $\mathrm{Na}_{2} \mathrm{CO}_{3} . \mathrm{CaSO}_{4}$ is more soluble than $\mathrm{CaCO}_{3}$ so it furnishes $\mathrm{Ca}$ that is more competitive for the exchange sites. Exchangeable $\mathrm{Na}$ may be replaced during the wetting and drying cycles, and leaching can remove the replaced $\mathrm{Na}$ if drainage is adequate. If the soil has a fluctuating water table, Na may move upward when the soil is water-saturated to recharge the exchange complex.

The ratio of $\mathrm{Ca}$ to $\mathrm{Mg}$ apparently changes as a claypan soil develops a progressively thicker friable surface layer (White 1964) and eventually loses most of the exchangeable $\mathrm{Na}$. The $\mathrm{Ca} / \mathrm{Mg}$ ratio decreases as the clays are dispersed and broken down, probably because $\mathrm{Mg}$ is released from the clay structure (Barshad 1960). Additional exchangeable $\mathrm{Mg}$ accumulates because grasses cycle more $\mathrm{Mg}$ than $\mathrm{Ca}$ to the surface in proportion to the exchangeable amounts in the soil (White 1971). The $\mathrm{Ca} / \mathrm{Mg}$ ratio may increase after the exchangeable $\mathrm{Na}$ content is negligible if $\mathrm{Ca}$ is present in soil minerals that weather. Some relict claypan soils may not have developed thick surface layers as outlined, but had developed a subsoil layer that dispersed briefly as the $\mathrm{Na}$ leached. However, the net effect on the present soil chemical nature probably is the same as outlined.

Exchangeable $\mathrm{K}$ and Na should cause about the same amount of dispersion. Some flocculated soils with considerable exchangeable $\mathrm{K}$ would be dispersed if the $\mathrm{K}$ were replaced by $\mathrm{Na}$ (Reeve et al. 1954). Most micas have two silica sheets that enclose either a gibbsite or brucite type sheet and interlayer $K$ that holds the different 2:1 units together. As water hydrates the interlayer space during weathering, first around the edges and then progressively into the center of the mineral, the $\mathbf{K}$ is released (Fanning and Kermidas 1977). Extraction of exchangeable cations is usually accomplished with $\mathrm{NH}_{4}$-acetate solutions which can replace some of the partially released $\mathbf{K}$ from the structure. This form of $\mathbf{K}$ does not help to form a shell of positive cations around the clay particles and does not contribute to dispersion. However, $\mathrm{K}$ could contribute if present in sufficient amounts.

\section{Structure Variations in Claypan Soils}

The dispersed claypan layer usually has columnar structure with 
either flat or rounded tops that lie below the low-Na, friable, thin surface layer. The columns are bordered and formed by vertically oriented desiccation cracks that create a polygonal network of cracks in the horizontal plane (White 1970). Distances across the columns are controlled by texture and the depth and rate of drying. Columns have smaller diameters in the upper part of the layer and, with depth, several small ones join together to form a larger column. During extreme droughts, the larger columns are surrounded by desiccation cracks, several centimeters in width, which may extend up to the surface. A network of smaller fracture surfaces is created inside the upper part of the large column and around the smaller columns. These smaller columns probably are less stable and change more from year to year than the large columns. In any event, a slight disturbance of the small columns will have little lasting effect upon the soil because the surrounding stable network of potential fractures will cause the disturbed soil to crack at about the same location in the next drying cycle. A minor disturbance has little if any effect on the larger columns. A mechanical treatment with a lasting effect on the soil needs to sufficiently alter the structure or some other property so that the original structure cannot reform rapidly.

Friable matcrial from the surface layer may move downward into natural fractures or man-made voids in the soil. The friable material creates a plane of weakness for the formation of a desiccation crack. In addition, partially dry subsoil is first remoistened adjacent to the friable fill because the fill has greater permeability. If the claypan is not completely rewet, the moistened volume would have the largest elasticity. The soil would stretch and fracture at the friable fill as the soil dries for many cycles of wetting and drying.

Columns may have vertical lengths of a few centimeters or several meters. Subsoils with high contents of $\mathrm{CaCO}_{3}, \mathrm{CaSO}_{4}$, or more soluble salts tend to develop indistinct edges along the lower parts of the column. Apparently, salt decreases the ability of the soil to develop a permanent network of fracture planes. Possibly, salt can move into the fracture planes to disrupt the tendency for them to reform in the same place during the next drying cycle. Probably for the same reason, the small blocky structure inside the columns is very weakly developed or absent. Thus, prerequisites are absent for an organized fracture system to control the contraction and expansion volume changes induced by wetting and drying.

Columnar and blocky structure are weakly developed in finetextured clay soil with low salt and organic matter contents. The clay has such a large volume change with wetting and drying that the individual fracture surface may form at different locations in each wetting and drying cycle. An exception occurs where the surface soil is very friable or wind drifted sands can fall into desiccation cracks.

\section{Detrimental Effects of Claypan Soils on Plants}

The most important detrimental effects appear to be limited plant-available water, poor soil physical conditions for root growth, high osmotic potential of the subsoil, and low plant nutrient levels and availability. Infiltration and hydraulic conductivity rates are low in the dispersed layer so that much of the precipitation ponds on the surface and evaporates. During prolonged periods with high precipitation, water does penetrate throughout the soil and rhizomatous plants expand into the panspots.

Soluble salts in moist subsoils are diluted by the water but, as plants remove water, salts are concentrated. This increases the osmotic potential and reduces the availability of water to plants. Most claypan areas have sufficient drainage to remove some of the soluble salts or the soils would not able to disperse. Thus, the salt effect probably is minimal unless saline soils are mixed with the claypan.

Root growth through the claypan occurs mostly along the edges of columns, where the resistance to penetration probably is least, according to Holmes and Stacy (1967). In addition, roots that follow cracks along the sides of columns are less likely to break or stretch than roots that go through columns at an angle. Roots may concentrate along the column sides because they are more moist and water soaks downward along structure boundaries (Krishna and Perumal 1948) more rapidly than through the columns. Roots growing through the columns may be constricted sufficiently by contracting soil to reduce growth (White 1977). If the columns are located at or slightly below the surface, the short warm-season grasses with extensive shallow root systems may not be able to withstand soil contraction forces.

Most claypan soils have too low an organic matter content to supply adequate nitrogen and phosphorus to growing plants (Wight et al. 1978a). Further, the ratio of the exchangeable cations is different than in most surrounding soils. Range vegetation may have sufficient genetic variability to develop natural ecotypes (Main 1974) that are suited for most claypan soils. High $\mathrm{pH}$ may reduce the solubility of phosphates to the extent that growth is limited by phosphorus supply if microbial or algae-fixed nitrogen is present.

\section{Possible Effects of Mechanical Treatments on Claypan Soils}

Mechanical treatments appear to be of three kinds or combinations of them: those that trap surface water, those that fracture the claypan and increase infiltration, and those that mix the pan layer with surface and/or subsoil layers. Water is trapped on or near the surface by contour furrowing, basin listing, terracing, or pitting. Ripping and subsoiling, if deep enough, disrupt the claypan layer. Deep plowing may mix the entire soil profile together (Bowser and Cairns 1967) or with the right combination of plows, invert a soil layer beneath other layers or between other layers, not necessarily in their original order (Botov 1959).

Mechanical treatments that retain precipitation on a part of the surface (Wight et al. 1978b) effectively change the soil microclimate. One part of the treated soil becomes drier and the other becomes more moist. Water penetration into the soil is decreased and increased in vertical parallel planes across the claypan soil tract. If the spacing between moist planes coincides with the natural distance across the large structural columns, soils may develop a more or less permanent crack system along the more moist locations. This condition is similar to the crack that develops between two rows of corn where the soil dries last as plant available water is used. Distances between parallel sets of cracks apparently can be controlled at least where alternate strips of fallow and crops occur (Swartz 1966). Parallel zones for water accumulation develop naturally in some soils (Worrall 1959). The distance between large cracks apparently increases with the depth of wetting and drying (White 1970).

Water concentrated in vertical parallel planes may duplicate the effect of trickle irrigation of soils (Bresler 1975). Salt tends to move into the drier parts of the soil and plant roots grow in the moist soil with the relatively low salt content. For this reason, laboratory analyses of soils which suggest that $\mathrm{Na}$ or the salt content has been reduced (Soiseth et al. 1974) need to be interpreted cautiously.

Disrupting the claypan structure by ripping probably causes the least possible mechanical mixing. If the soil is moist, the disruption would have minimal effect because it would not disrupt structure sufficiently to destroy the natural fracture system that developed the structure. A claypan with a high exchangeable $\mathrm{Na}$ and low salt content reforms rapidly as can be observed in cultivated fields. If the exchangeable Na content and dispersion forces are low, ripping may open the claypan sufficiently so that some low-Na surface material falls downward. This fill material probably would not disperse so infiltration would increase permanently along the plane. Dispersion of the fill probably would occur rapidly if the claypan has a large content of exchangeable $\mathrm{Na}$.

Subsoil with gypsum $\left(\mathrm{CaSO}_{4} .2 \mathrm{H}_{2} \mathrm{O}\right)$ that is mixed into a claypan with a moderate or low amount of exchangeable $\mathrm{Na}$ will cause flocculation. Gypsum releases $\mathrm{Ca}$ that can replace the exchangeable $\mathrm{Na}$ which then leaches from the soil if drainage is adequate. Soil 
improvement from deep plowing of claypan soils depends on this leaching. If drainage is inadequate, the gypsum will gradually move downward as the water table fluctuates. Na moves upward more rapidly than $\mathrm{Ca}$ when the water table rises so that it remains and causes dispersion. Thus, improvement from mixing the dispersed layer with either subsoil or surface layers depends upon the properties of each layer and upon the drainage of $\mathrm{Na}$ from the soil.

Each area of claypan soil will have slightly different sets of variables which need to be evaluated. Vegetation can be used as a guide to the salt and exchangeable sodium content in the rooting zone. Species such as inland saltgrass (Distichlis spicata stricta) that grow on saline soils are a guide to soils which have a temporary high water table. These saline soils will not be benefited significantly by mechanical treatment until subsoil drainage has been improved. Nonsaline soils, nearly devoid of vegetation and with a claypan, can be improved by mechanical treatments which increase water infiltration. The success of this treatment increases as the proportion of the area with a dense vegetative cover increases. If a thick stand is present over the area, mechanical treatments may improve water infiltration by disrupting the claypan and by reducing runoff.

\section{Literature Cited}

Barshad, I. 1960. Significance of the presence of exchangeable magnesium ions in acidified clays. Sci. 131:988-990.

Botov, T.G. 1959. Radical improvement of solonetzic and podzolic soils by redistribution of the soil horizons. Soviet Soil Sci. 1959:59I-596.

Bowser, W.E., and R.R. Cairns. 1967. Some effects of deep plowing a solonetz soil. Canadian J. Soil Sci. 47:239-244.

Bresler, E. 1975. Two-dimensional transport of solutes during nonsteady infiltration from a trickle source. Soil Sci. Soc. Amer. Proc. 39:604-613.

Chi, C.L., W.W. Emerson, and D.G. Lewis. 1977. Exchangeable calcium, magnesium, and sodium and the dispersion of the illite in water. II Dispersion of illite in water. Aust. J. Soil Res. 28:255-262.

Clark, J.S. 1966. The distribution constant for exchange of calcium and magnesium in Wyoming bentonite. Can. J. Soil Sci. 46:271-280.

Fanning, D.S., and V.Z. Keramidas. 1977. Micas. In: J.B. Dixon and S.B. Weed. Minerals in Soil Environments. p. 196-258. Soil Sci. Soc. Amer., Madison, Wisc.

Frenkel, H., J.O. Goertzen, and J.D. Rhoades. 1978. Effects of clay type and content, exchangeable sodium percentage, and electrolyte concen- tration on clay dispersion and hydraulic conductivity. Soil Sci. So Amer. Proc. 42:32-39.

Holmes, J.W., and H.C.T. Stacy. 1967. On the domed structure an anisotropy of the B horizon of the solodized solonetz. Aust. J. Soil Re 6:149-157.

Krishna, P.G., and S. Perumal. 1948. Structure of Black Cotton Soils of th Nezamsager Project Area. Hyderabad State, India. Soil Sci. 66:29-3i

Main, J.L. 1974. Differential response to magnesium and calcium by nativ populations of Agropyron spicatum. Amer. J. Bot. 61:931-933.

McAtee, J.L., Jr. 1958. Heterogeneity in montmorillonite. Clays and $\mathrm{Cla}$ Minerals. NAS-NRC Publ. 566:279-288.

Nakayama, F.S. 1969. Theoretical considerations of the calcium sulfat bicarbonate-carbonate interrelation in soil solution. Soil Sci. Soc. Ame 33:668-672.

Reeve, R.C., C.A. Bower, R.H. Brooks, and F.B. Gschwend. 1954. comparison of the effects of exchangeable sodium and potassium upo the physical condition of soils. Soil Sci. Soc. Amer. Proc. 18:130-13:

Singh, S.S., and B.R. Moorthy. 1965. Cation exchange equilibrium studi in soil systems containing calcium, magnesium, potassium, and sodiun Lantboukshogskolaus Annales 31:92-101.

Soil Survey Staff. 1975. Soil Taxonomy. Soil Conservation Service. U.: Dep. Agr. Handbk. 436.

Soiseth, R.J., J.R. Wight, and J.K. Aase. 1974. Improvement of panspo (Solenetzic) range sites by contour furrowing. J. Range Manage. 27:10 110.

Swartz, G.L. 1966. Modification of the cracking pattern on a Black Eart of the Darling Downs, Queensland. Queensland J. Agr. Animal Sc 23:279-285.

White, E.M. 1961. Calcium-solodi or planosol genesis from solodize solonetz. Soil Sci. 91:175-177.

White, E.M. 1964. Morphological-chemical relationships of some thin horizon solodized soils derived from moderately fine material on well-drained slope. Soil Sci. 98:256-263.

White, E.M. 1970. Giant desiccation cracks in central South Dakota soil Soil Sci. 110:71-73.

White, E.M. 1971. Grass cycling of calcium, magnesium, potassium, an sodium in solodization. Soil Sci. Soc. Amer. Proc. 35:390-31I.

White, E.M. 1977. Effect on plant growth of constricting forces applied $t$ the upper parts of roots. Agron. J. 69:437-439.

Wight, J.R., E.L. Neff, and R.J. Soiseth. 1978a. Maximizing forage pr duction on fine-textured, sodic-affected range sites in the Northern Gre: Plains. Rangeman's J. 5:42-44.

Wight, J.R., E.L. Neff, and R.J. Soiseth. 1978b. Vegetation response 1 contour furrowing. J. Range Manage. 31:97-101.

Worrall, G.A. 1959. The Butana grass patterns. J. Soil Sci. 10:37-53. 